\title{
Patient Recovery from COVID-19 Infections: Follow-Up of Hair, Nail, and Cutaneous Manifestations
}

\author{
Rattapon Thuangtong $\left(\mathbb{D},{ }^{1}\right.$ Nasikarn Angkasekwinai $(\mathbb{D})^{2}$ Charussri Leeyaphan $\left(\mathbb{D},{ }^{1}\right.$ \\ Daranporn Triwongwaranat $\mathbb{D},{ }^{1}$ Kanchalit Thanomkitti $\mathbb{D}^{1},{ }^{1}$ Kanyalak Munprom $\mathbb{D}^{\mathbb{D}}{ }^{1}$ \\ and Kanokvalai Kulthanan (iD) \\ ${ }^{1}$ Department of Dermatology, Faculty of Medicine Siriraj Hospital, Mahidol University, Bangkok, Thailand \\ ${ }^{2}$ Division of Infectious Diseases and Tropical Medicine, Faculty of Medicine Siriraj Hospital, Mahidol University, Bangkok, Thailand
}

Correspondence should be addressed to Daranporn Triwongwaranat; d.triwongwaranat@gmail.com

Received 5 February 2021; Accepted 9 June 2021; Published 25 June 2021

Academic Editor: Arjen F. Nikkels

Copyright (C) 2021 Rattapon Thuangtong et al. This is an open access article distributed under the Creative Commons Attribution License, which permits unrestricted use, distribution, and reproduction in any medium, provided the original work is properly cited.

\begin{abstract}
Background. COVID-19 is a pandemic disease worldwide. Although cutaneous manifestations may present in affected patients, there have been limited studies on the cutaneous findings and hair and nail abnormalities after discharge. Objective. To establish the cutaneous manifestations, hair and scalp disorders, and nail abnormalities in patients who recovered from COVID-19 infections. Methods. A retrospective chart review and telephone interviews were conducted to determine the cutaneous manifestations, hair and scalp disorders, and nail abnormalities of patients aged over 18 years who were diagnosed with COVID-19 infections at Siriraj Hospital, Bangkok, Thailand, between January and June 2020. Results. Ninety-three patients with prior COVID-19 infections participated in the study. The COVID-19 severity had been mild for most (71\%). Cutaneous manifestations were reported in 8 patients $(8.6 \%)$, with the common skin conditions being maculopapular rash and urticaria. The onsets of the skin conditions were before admission (1\%), during admission (4.3\%), and after discharge (3.2\%). Increased hair shedding was also reported in 22 patients (23.7\%), with a female predominance. Three patients were affected during admission, while the others were affected after discharge. The patients with moderate, severe, and critical COVID-19 infections experienced significantly more hair shedding than those with asymptomatic and mild diseases. Only 2 patients with mild COVID-19 disease reported nail abnormalities (chromonychia and brittle nails). Conclusions. Cutaneous manifestations, hair disorders, and nail abnormalities can occur in patients with COVID-19 after their discharge from hospital. Patients should therefore be followed up in anticipation of dermatological problems.
\end{abstract}

\section{Introduction}

Coronavirus disease 2019 (COVID-19), a pandemic disease that emerged in December 2019, is caused by severe acute respiratory syndrome coronavirus 2 (SARS-CoV-2) [1]. The main clinical presentation is flu-like symptoms, such as fever, cough, and sore throat. The infection can transmit into the lower respiratory tract, leading to pneumonia in some patients. In addition, organ dysfunction, acute respiratory distress syndrome, and coagulation disorders may develop, resulting in a high mortality rate. According to the COVID-19 Treatment Guidelines of the National Institutes of Health, disease severity is classified into 5 groups: asymptomatic, mild, moderate, severe, and critical [2].

Besides the respiratory system, one of the many other organs that can be affected is the skin. The cutaneous manifestations of COVID-19 can present in various clinical patterns, and their classification into the following 5 subtypes has been proposed: maculopapular rash, urticarial lesion, pseudo-chilblain, vesicular eruption and livedo, and necrosis [3]. Their onset typically occurs before and during admission, but cutaneous findings after discharge have been reported by many studies [4-10]. Although hair and nail disorders may also occur late after recovery from a COVID-19 
infection, studies on the hair and nail problems of patients infected with the SARS-CoV-2 virus are rare [11-16]. Telephone interview is one tool to assess the patient's condition in this on-going COVID-19 pandemic to comply with infectious disease control policy. Thus, this study is aimed at evaluating the cutaneous manifestations, hair and scalp disorders, and nail abnormalities of patients recovered from COVID-19 infections.

\section{Methods}

Before its commencement, the study was approved by the Siriraj Institutional Review Board. This retrospective, single-center study used a combination of chart reviews and telephone interviews to establish the cutaneous manifestations, hair and scalp disorders, and nail abnormalities of patients aged over 18 years who were diagnosed with COVID-19 infections at Siriraj Hospital, Bangkok, Thailand, between January and June 2020. The COVID-19 diagnoses of all of the patients had been confirmed by positive reverse transcription polymerase chain reaction tests. A review was performed of the demographic data, clinical manifestations, treatments, and clinical courses of the COVID-19 infections, as detailed in the patients' medical records. In addition, a structured questionnaire was used to conduct telephone interviews at the end of September 2020. The study was conducted in this period because the skin manifestations in the recovery phase may occur in 3-4 months after infection, such as telogen effluvium (TE), but not too long to forget their skin conditions.

Descriptive statistics (percentages, frequency, mean, median, standard deviation, minimum, and maximum) were calculated. Fisher's exact test and the Mann-Whitney $U$ test were used for qualitative and quantitative variables, respectively. Statistical significance was set at 0.05 . The statistical data were analyzed using PASW Statistics for Windows (version 18.0; SPSS Inc., Chicago, Ill., USA).

\section{Results}

In all, 115 patients diagnosed with COVID-19 infections were admitted to our hospital during the study period. The demographic data and clinical characteristics of the 93 patients who participated in this study are listed in Table 1. Their mean age was $40.8 \pm 15.1$ years (range, $21-83$ years), and the majority were males (58.1\%). One-third had underlying diseases, such as hypertension, diabetes, dyslipidemia, and allergic rhinitis. Two patients had previously been diagnosed as having psoriasis, but the diseases were well controlled prior to their COVID-19 infections. The most common presentation of COVID-19 infection was upper respiratory tract symptoms. The disease severities of COVID-19 were chiefly graded as mild (71\%), followed by severe (14\%) and moderate (9.7\%). Four patients developed acute respiratory distress syndrome, and only one patient was asymptomatic. All patients with any severity of COVID-19 infection were admitted to the hospital to monitor their clinical symptoms, to administer medications, and to prevent the spread of the disease. The median hospitaliza-
TABLE 1: Clinical characteristics of COVID-19 infected patients.

\begin{tabular}{|c|c|}
\hline Clinical characteristics $($ total $=93$ ) & $\begin{array}{c}\text { Number/total } \\
(\%)\end{array}$ \\
\hline \multicolumn{2}{|l|}{ Gender } \\
\hline Female & $39 / 93(41.9)$ \\
\hline Male & $54 / 93(58.1)$ \\
\hline Age at onset: mean $\pm \mathrm{SD}$ (years) & $40.8 \pm 15.1$ \\
\hline Underlying diseases* & $35 / 93(37.6)$ \\
\hline Hypertension & $13 / 35(37.1)$ \\
\hline Diabetes & $12 / 35(34.3)$ \\
\hline Dyslipidemia & $6 / 35(17.1)$ \\
\hline Allergic rhinitis & $3 / 35(8.6)$ \\
\hline Old pulmonary tuberculosis & $2 / 35(5.7)$ \\
\hline Cancer & $2 / 35(5.7)$ \\
\hline Stroke & $2 / 35(5.7)$ \\
\hline Chronic hepatitis B infection & $2 / 35(5.7)$ \\
\hline Psoriasis & $2 / 35(5.7)$ \\
\hline Thalassemia & $1 / 35(2.9)$ \\
\hline Alzheimer's disease & $1 / 35(2.9)$ \\
\hline \multicolumn{2}{|l|}{ Presented symptoms } \\
\hline Asymptomatic & $1 / 93(1.0)$ \\
\hline Upper respiratory tract & $66 / 93(71.0)$ \\
\hline Lower respiratory tract & $26 / 93(28.0)$ \\
\hline \multicolumn{2}{|l|}{ Disease severity ${ }^{\ddagger}$} \\
\hline Asymptomatic & $1 / 93(1.0)$ \\
\hline Mild & $66 / 93(71.0)$ \\
\hline Moderate & $9 / 93(9.7)$ \\
\hline Severe & $13 / 93(14.0)$ \\
\hline Critical state & $4 / 93(4.3)$ \\
\hline \multicolumn{2}{|l|}{ Laboratory investigation } \\
\hline Leukopenia & $25 / 93(26.9)$ \\
\hline Leukocytosis & $5 / 93(5.4)$ \\
\hline Abnormal liver function test & $17 / 91(18.7)$ \\
\hline Elevated C-reactive protein & $35 / 80(43.8)$ \\
\hline Abnormal chest X-ray & $26 / 93(28.0)$ \\
\hline $\begin{array}{l}\text { Duration of hospitalization: median (min, max; } \\
\text { days) }\end{array}$ & $6.0(2.0,53.0)$ \\
\hline
\end{tabular}

${ }^{*}$ One patient could have more than one disease. ${ }^{\ddagger}$ The severity of COVID-19 was classified according to the COVID-19 Treatment Guidelines of the National Institutes of Health.

tion duration was 6 days (range, 2-53 days). The median duration between the date of the COVID-19 diagnoses and the study interview was 170 days (range, 142-184 days).

3.1. Cutaneous Manifestations (Table 2). Cutaneous manifestations were reported in 8 patients $(8.6 \%)$, with half of those having a mild severity of COVID-19 infection. Maculopapular rash was reported in 3 patients; its onset was during admission in the case of 2 patients and 7 days after hospital discharge for the third patient. Acute urticaria was reported in 2 patients. The condition developed 3 days before the COVID-19 diagnosis in one patient with a mild disease severity, but 120 days after discharge for the other patient, 


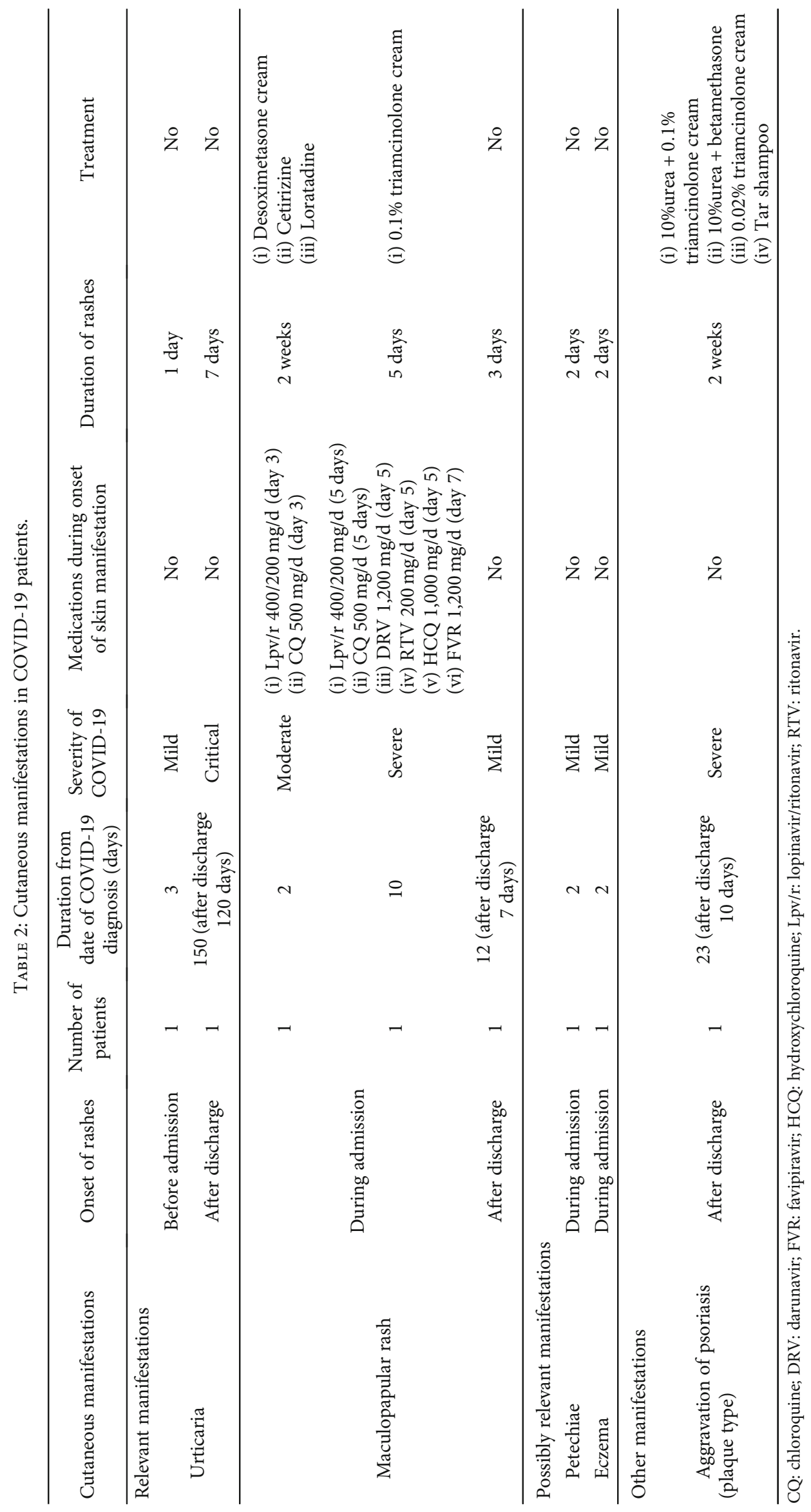


TABLE 3: Hair disorders in COVID-19 patients.

\begin{tabular}{|c|c|c|c|c|c|}
\hline $\begin{array}{l}\text { Clinical manifestations and laboratory investigations: } \\
\text { Number/total (\%) }\end{array}$ & $\begin{array}{l}\text { Increased hair } \\
\text { shedding }\end{array}$ & $\begin{array}{l}\text { No increased hair } \\
\text { shedding }\end{array}$ & $\begin{array}{l}\text { Crude OR }(95 \% \\
\qquad \text { CI })^{*}\end{array}$ & $\begin{array}{l}\text { Adjusted OR } \\
\quad(95 \% \mathrm{CI})\end{array}$ & $\begin{array}{c}p \\
\text { value }\end{array}$ \\
\hline Severity of COVID-19 $(n=93)$ & $22(23.7)$ & $71(76.3)$ & & & \\
\hline Asymptomatic-mild $(n=67)$ & $11(16.4)$ & $56(83.6)$ & $3.7(1.4,10.3)$ & $5.8(1.8,18.9)$ & 0.008 \\
\hline Moderate-severe-critical state $(n=26)$ & $11(42.3)$ & $15(57.7)$ & & & \\
\hline \multicolumn{6}{|l|}{ Gender } \\
\hline Female $(n=39)$ & $14(35.9)$ & $25(64.1)$ & $3.2(1.2,8.7)$ & $5.0(1.6,15.9)$ & 0.018 \\
\hline Male $(n=54)$ & $8(14.8)$ & $46(85.2)$ & & & \\
\hline Age at onset: mean $\pm \mathrm{SD}$ (years) & $43.5 \pm 16.8$ & $40.0 \pm 14.5$ & & & 0.339 \\
\hline \multicolumn{6}{|l|}{ Laboratory investigations } \\
\hline Leukopenia $(n=25)$ & $3(12.0)$ & $22(88.0)$ & & & 0.222 \\
\hline Leukocytosis $(n=5)$ & $2(40.0)$ & $3(60.0)$ & & & \\
\hline Abnormal liver function test $(n=17)$ & $6(35.3)$ & $11(64.7)$ & & & 0.209 \\
\hline Elevated C-reactive protein $(n=35)$ & $12(34.3)$ & $23(65.7)$ & & & 0.091 \\
\hline
\end{tabular}

${ }^{*}$ The data are expressed as odds ratio with $95 \%$ confidence interval. ${ }^{* *}$ Multivariable odds ratio was calculated by stepwise logistic regression. OR: odds ratio; CI: confidence interval.

who had had a critical disease state. Both patients had spontaneous remission within one week. No other potential causes of maculopapular rash or urticaria-such as a drug or an autoimmune disease-were detected in the 5 patients. Other possibly relevant cutaneous manifestations reported were petechiae and eczema. Each was found in only 1 patient with mild COVID-19 disease during admission. Psoriasis as an underlying disease was reported in 2 patients; disease aggravation occurred in one of those patients 10 days after COVID-19 discharge.

3.2. Hair and Scalp Disorders (Table 3). Increased hair shedding was reported in 22 patients (23.7\%). Of those, 12 patients $(12.9 \%)$ reported a history of hair shedding of more than 100 hairs on regular days or more than 200 hairs on washing days. Hair shedding occurred after hospital discharge in 19 patients ( $87 \%$ of the affected cases), for whom the median time from the date of COVID-19 diagnosis was 42 days (range, 6-105 days). Three patients (13\%) reported active hair shedding during admission, with a median time from the date of COVID-19 diagnosis of 12 days (range, 316 days). No other causes of anagen or telogen effluvium, such as a drug or an autoimmune disease, were detected in the 22 patients.

Increased hair shedding was found to be related with the severity of the COVID-19 disease. Patients with moderate, severe, and critical diseases had significantly greater hair shedding than those with asymptomatic and mild diseases (42.3\% vs. 16.4\%; $p=0.008$; COR, 3.7; 95\% CI, 1.4-10.3). Females also experienced significantly more hair shedding than males ( $35.9 \%$ vs. $14.8 \%$; $p=0.018$; COR, $3.2 ; 95 \% \mathrm{CI}$, 1.2-8.7). No other investigated results were associated with increased hair shedding.

Scalp disorders were reported in 3 patients; 2 had an aggravation of seborrheic dermatitis, and the third had deterioration of scalp psoriasis.
3.3. Nail Abnormalities. Only 2 patients with mild disease reported nail abnormalities. One patient observed transverse yellow-brown banding on the distal nail plates of all toenails 3 months after discharge. She denied a history of the use of concomitant medications or nail polish. The second patient complained of having brittle fingernails 3 months after discharge. Both patients still had their abnormal nails at the time of interview (about 5 months after their COVID-19 diagnoses).

\section{Discussion}

COVID-19 infection has been spreading globally as a new pandemic disease since November 2019. As our hospital is one of the largest tertiary centers in Thailand, all COVID19 patients hospitalized there have different severities of disease. Thus, cutaneous manifestations were carefully observed by experienced physicians during admission.

An ever-increasing number of studies are reporting skin manifestations associated with COVID-19 infections. In our work, skin and hair manifestations were found in only 7 (7.5\%) patients during admission, but 24 (25.8\%) other cases developed after hospital discharge (19,3, and 2 patients with hair, skin, and nail conditions, respectively). Increased hair shedding was found 1-2 months after COVID-19 infection. Maculopapular rash occurred during, or shortly after, a COVID-19 infection; this was in marked contrast with urticaria, which developed up to 5 months after infection. To date, nail changes have been reported rarely. Based on our literature review, the present study is the first to report color discoloration of the nails in a patient who had had a COVID-19 infection.

There were no cases with pseudo-chilblain or livedoid lesions, as reported in other regions, especially Europe [17]. Only urticaria and maculopapular rash were found in this study, which corresponds with the findings of other studies 
in tropical countries $[18,19]$. This might be explained by climate differences and/or a lower severity of COVID-19 infections. Furthermore, vesicular eruption or other reported cutaneous manifestations such as erythema multiforme were not found in our study. This might be because of a small number of patients in this study.

The cutaneous lesions could be seen before admission, during admission, or after discharge. Our study found one patient with an urticarial lesion before the COVID-19 diagnosis. The lesion might have been a reaction to viral infection or a preceding symptom of COVID-19, similar to other reports $[20,21]$. As to the cases whose skin rash occurred during admission, drug-induced rash should be considered a differential diagnosis from viral-related cutaneous findings. However, as no potential causative drug was found in our patients, the maculopapular rash might have been caused by the COVID-19 infection. There have been reports of late-onset skin manifestations in patients with previous COVID-19 infections, such as urticaria [4], urticarial vasculitis [5], maculopapular rash [6, 7], acute generalized exanthematous pustulosis-like [8], Kawasaki-like [9], and acral necrosis [10]. This study also found one patient developed urticaria 120 days after discharge. The association between this symptom and COVID-19 infection was unknown because of the delayed onset. A previous study reported some cutaneous manifestations associated with the severity and outcomes of COVID-19. Maculopapular rash was frequently reported in moderate severity with good outcome. Retiform purpura was associated with more severe disease and worse prognosis [22]. However, from our study, urticaria and maculopapular rash could be observed in any severity of COVID-19 except asymptomatic and had 100\% survival rate.

We also studied hair disorders in patients with COVID19 infections. Onset of increased hair shedding during admission was detected in 3 patients (3.2\%), who had different severities of COVID-19 infection, ranging from mild to severe. In general, the cause of a sudden onset of hair loss might be anagen effluvium [23]. Currently, only one reported case had anagen effluvium associated with a COVID-19 infection [24]. However, this condition frequently affects almost all of the scalp hair, unlike our patients. Additionally, from our literature review, there have been no reports of hair shedding being induced by the medications used for COVID19 therapy within a few weeks of their initiation.

In our study, the late onset of increased hair shedding was found in $20.4 \%$ of COVID-19 patients. TE would be of most concern following a systemic infection [25]. Long-term use of lopinavir/ritonavir has been reported to induce TE in human immunodeficiency virus-infected patient [26]. However, all treatments used with our COVID-19 patients were prescribed for short durations (5-14 days). Thus, TE in our patients might have resulted from viral infections or stressful events rather than drug-induced hair loss, as mentioned in other studies $[12,15,16]$. It has been proposed elsewhere that an infection or proinflammatory cytokines might induce an immediate shift from the anagen phase to the telogen phase of hair follicle growth, resulting in TE [15].

Our study revealed that two statistically significant factors determined excessive hair loss in COVID-19 patients.
Firstly, the severity of the COVID-19 disease strongly influenced the risk of increased hair shedding. The greater the COVID-19 severity was, the more pronounced was the hair loss. The second factor was the gender of the patient, given that hair shedding strongly predominated in females. Thus, patients with COVID-19 infections should be warned about the possibility of hair loss and have their hair condition closely monitored during admission and after hospital discharge. This is especially important for patients who are female or have more severe infections.

Nail abnormalities associated with COVID-19 have been reported in few studies. Beau's line [11], Mee's line [13], and red half-moon nails [14] have been observed. It has been hypothesized that COVID-19 infections induce nail matrix and vascular injuries. This study is the first to report a yellow-brown chromonychia in a patient who had a mildly severe COVID-19 infection. It appeared 5 months after the onset of the COVID-19 symptoms. Chromonychia has been associated with some systemic conditions (such as Kawasaki disease), but none were found in our patient. The mechanism of chromonychia remains unclear; perhaps nail plate keratinization may be abnormal, or the chromonychia is a consequence of a vascular disorder such as vasculitis. The chromonychia may also be a late manifestation of a red half-moon nail, which has previously been reported in patient with COVID-19 infections [14]. The different color$\mathrm{s}$-from red to orange to brown-may reflect a sequence of vascular inflammation followed by residual coloration after resolution. Red half-moon nails may be underrecognized in their early phase, but later found as a yellow chromonychia at the distal end of the nails. Thus, chromonychia might be one late-onset nail abnormality related with COVID-19 infections.

The limitations of this study were that it was conducted at a single center, it had a relatively small sample size, and most of its data were collected by telephone interviews. As the physicians could not assess the actual skin conditions after hospital discharge, the findings might have been influenced by recall bias. We suggest that photography and telemedicine could be used to decrease the bias gap. Furthermore, this study was conducted with an observation period about 6 months. The long-term follow-up should be considered to observe skin condition.

In conclusion, cutaneous manifestations, hair disorders, and nail abnormalities can occur after hospital discharge. Subsequent monitoring of patients is therefore advisable. Telephone interviews are one of the possible, useful, followup methods.

\section{Data Availability}

The data used to support the findings of this study are available from the corresponding author upon request.

\section{Conflicts of Interest}

All authors declare that there are no conflicts of interest related to this study. 


\section{References}

[1] N. Zhu, D. Zhang, W. Wang et al., "A novel coronavirus from patients with pneumonia in China, 2019," The New England Journal of Medicine, vol. 382, no. 8, pp. 727-733, 2020.

[2] National Institutes of Health, Coronavirus Disease 2019 (COVID-19) Treatment Guidelineshttps://www .covid19treatmentguidelines.nih.gov/.

[3] C. Galván Casas, A. Català, G. Carretero Hernández et al., "Classification of the cutaneous manifestations of COVID19: a rapid prospective nationwide consensus study in Spain with 375 cases," The British Journal of Dermatology, vol. 183, no. 1, pp. 71-77, 2020.

[4] S. Recalcati, "Cutaneous manifestations in COVID-19: a first perspective," Journal of the European Academy of Dermatology and Venereology, vol. 34, no. 5, pp. e212-e213, 2020.

[5] N. Skroza, N. Bernardini, V. Balduzzi et al., "A late-onset widespread skin rash in a previous COVID-19-infected patient: viral or multidrug effect?," Journal of the European Academy of Dermatology and Venereology, vol. 34, no. 9, pp. e438e439, 2020.

[6] M. Herrero-Moyano, T. M. Capusan, M. Andreu-Barasoain et al., "A clinicopathological study of eight patients with COVID-19 pneumonia and a late-onset exanthema," Journal of the European Academy of Dermatology and Venereology, vol. 34, no. 9, pp. e460-e464, 2020.

[7] A. Reymundo, A. Fernáldez-Bernáldez, A. Reolid et al., "Clinical and histological characterization of late appearance maculopapular eruptions in association with the coronavirus disease 2019. A case series of seven patients," Journal of the European Academy of Dermatology and Venereology, vol. 34, no. 12, pp. e755-e757, 2020.

[8] A. Ayatollahi, R. M. Robati, K. Kamyab, and A. Firooz, "Lateonset AGEP-like skin pustular eruption following COVID-19: a possible association," Dermatologic Therapy, vol. 33, no. 6, p. e14275, 2020.

[9] J. Toubiana, C. Poirault, A. Corsia et al., "Kawasaki-like multisystem inflammatory syndrome in children during the covid19 pandemic in Paris, France: prospective observational study," BMJ, vol. 369, p. m2094, 2020.

[10] R. Balestri, S. Termine, G. Rech, and C. R. Girardelli, "Late onset of acral necrosis after SARS-CoV-2 infection resolution," Journal of the European Academy of Dermatology and Venereology, vol. 34, no. 9, pp. e448-e449, 2020.

[11] S. Alobaida and J. M. Lam, "Beau lines associated with COVID-19," Canadian Medical Association Journal, vol. 192, no. 36, p. E1040, 2020.

[12] M. Domínguez-Santás, L. Haya-Martínez, D. FernándezNieto, J. Jiménez-Cauhé, A. Suárez-Valle, and B. Díaz-Guimaraens, "Acute telogen effluvium associated with SARSCoV-2 infection," Australian Journal of General Practice, vol. 49, 2020.

[13] D. Fernandez-Nieto, J. Jimenez-Cauhe, D. Ortega-Quijano, B. Diaz-Guimaraens, M. Dominguez-Santas, and J. MartinezRubio, "Transverse leukonychia (Mees' lines) nail alterations in a COVID-19 patient," Dermatologic Therapy, vol. 33, no. 6, p. e13863, 2020.

[14] I. Neri, A. Guglielmo, A. Virdi, V. Gaspari, M. Starace, and B. M. Piraccini, "The red half-moon nail sign: a novel manifestation of coronavirus infection," Journal of the European Academy of Dermatology and Venereology, vol. 34, no. 11, pp. e663e665, 2020.
[15] O. M. Moreno-Arrones, A. Lobato-Berezo, A. Gomez-Zubiaur et al., "SARS-CoV-2-induced telogen effluvium: a multicentric study," Journal of the European Academy of Dermatology and Venereology, vol. 35, no. 3, pp. e181-e183, 2021.

[16] Y. Miyazato, S. Morioka, S. Tsuzuki et al., "Prolonged and lateonset symptoms of coronavirus disease 2019," Open Forum Infectious Diseases, vol. 7, no. 11, p. ofaa507, 2020.

[17] G. Daneshgaran, D. P. Dubin, and D. J. Gould, "Cutaneous manifestations of COVID-19: an evidence-based review," American Journal of Clinical Dermatology, vol. 21, no. 5, pp. 627-639, 2020.

[18] P. Rerknimitr, C. Theerawattanawit, P. Lertpichitkul et al., "Skin manifestations in COVID-19: the tropics experience," The Journal of Dermatology, vol. 47, no. 12, pp. e444-e446, 2020.

[19] P. Punyaratabandhu and P. Chirachanakul, "Cutaneous eruption in COVID-19-infected patients in Thailand: an observational descriptive study," The Journal of Dermatology, vol. 48, no. 1, pp. 14-20, 2021.

[20] C. van Damme, E. Berlingin, S. Saussez, and O. Accaputo, "Acute urticaria with pyrexia as the first manifestations of a COVID-19 infection," Journal of the European Academy of Dermatology and Venereology, vol. 34, no. 7, pp. e300-e301, 2020.

[21] D. Henry, M. Ackerman, E. Sancelme, A. Finon, and E. Esteve, "Urticarial eruption in COVID-19 infection," Journal of the European Academy of Dermatology and Venereology, vol. 34, no. 6, pp. e244-e245, 2020.

[22] P. Jamshidi, B. Hajikhani, M. Mirsaeidi, H. Vahidnezhad, M. Dadashi, and M. J. Nasiri, "Skin manifestations in COVID-19 patients: are they indicators for disease severity? A systematic review," Frontiers in Medicine, vol. 8, 2021.

[23] A. J. Kanwar and T. Narang, "Anagen effluvium," Indian Journal of Dermatology, Venereology and Leprology, vol. 79, no. 5, pp. 604-612, 2013.

[24] M. Shanshal, "COVID-19 related anagen effluvium," The Journal of Dermatological Treatment, pp. 1-2, 2020.

[25] J. T. Headington, “Telogen effluvium," Archives of Dermatology, vol. 129, no. 3, pp. 356-363, 1993.

[26] J. Borrás-Blasco, A. Belda, D. Rosique-Robles, E. Casterá, J. Abad, and I. Amorós-Quiles, "Hair loss induced by lopinavir-ritonavir," Pharmacotherapy, vol. 27, no. 8, pp. 12151218, 2007. 